\title{
Knowledge, Attitude and Practice of Pediatricians and Pharmacists in Riyadh City toward the use of Sugar free Medications
}

\author{
${ }^{1}$ Omar A Bawazir, ${ }^{2}$ Bandar Alsuwayt, ${ }^{3}$ Waleed Alqahtani, ${ }^{4}$ Ahmad Al-Dhafiri, ${ }^{5}$ Mosleh Al-Shamrani
}

\begin{abstract}
Objective: This study was intended to assess the knowledge, attitude and practice of pediatricians and pharmacists about sugar free medications (SFMs) and their impact on oral health.

Materials and methods: Self-administered close ended questionnaire was handed out to all pediatricians and pharmacists in five tertiary hospitals in Riyadh (King Khalid University Hospital, King Saud Medical City, King Fahad Medical City, Prince Sultan Medical Military City, Security Forces Hospital) to investigate the knowledge, attitude and practice concerning SFMs.
\end{abstract}

Results: Eighty-five pediatricians and 77 pharmacists participated in this study. The results showed that pediatricians and pharmacists have a good knowledge, but negative attitude toward SFMs. Only (5.9\%) of pediatricians had formal undergraduate training which is significantly lower than pharmacists $(15.6 \%)(p=0.04)$. One-third of pediatricans and pharmacists prescribe or dispense SFMs. The most influencing factors toward prescription (pediatrician) of SFMs was the medical status of the patient $(70.6 \%)$, while the most influencing factor of dispensing (pharmacists) SFMs was the availability in the pharmacy (64.9\%). Two-third of pediatricians $(67 \%)$ guide the parents about the risk associated with sugarcontaining medications (SCMs) which is significantly higher than pharmacists $(p<0.0001)$. Also, $53 \%$ of pediatricians recommend oral hygiene instructions when prescribing SCMs which is also significantly higher than pharmacists $(p=0.002)$.

Conclusion: There is a considerable knowledge about SFMs and its impact on dental caries, among pediatricians and pharmacists participated in this study. However, their attitude toward prescribing or dispensing SFMs was not positive and

\footnotetext{
${ }^{1}$ Assistant Professor, ${ }^{2,4}$ Dentist, ${ }^{3}$ Intern, ${ }^{5}$ Consultant

${ }^{1}$ Department of Pediatric Dentistry and Orthodontics, College of Dentistry, King Saud University, Riyadh, Saudi Arabia

${ }^{2,4}$ Hafer Al-Batin Dental Center, Ministry of Health, Hafer Al-Batin Saudi Arabia

${ }^{3}$ College of Dentistry, King Saud University, Riyadh, Saudi Arabia

${ }^{5}$ Department of Pediatric Dentistry, King Saud Medical City Riyadh, Saudi Arabia
}

Corresponding Author: Omar A Bawazir, Assistant Professor Department of Pediatric Dentistry and Orthodontics, College of Dentistry, King Saud University, PO Box 60169, Riyadh 11545 Saudi Arabia, e-mail: obawazir@ksu.edu.sa may be linked to the gap in knowledge. Further training and education of healthcare providers regarding the use of SFMs and its negative impact on dental caries has to be reiterated.

Keywords: Dental caries, Child, Pediatrician, Pharmacist, Sugar free medication.

How to cite this article: Bawazir OA, Alsuwayt B, Alqahtani W, Al-Dhafiri A, Al-Shamrani M. Knowledge, Attitude and Practice of Pediatricians and Pharmacists in Riyadh City toward the use of Sugar free Medications. J Contemp Dent Pract 2014; 15(6):755-760.

\section{Source of support: Nil}

Conflict of interest: None

\section{INTRODUCTION}

Dental caries is one of the most common oral diseases in children with a multifactorial etiology comprising of microbiota, diet and host response. Sugar and especially sucrose serves as a substrate for fermentation of the oral microbiota, in addition to influencing the production of acids and the type and amount of biofilm. ${ }^{1}$ Several liquid medications are frequently prescribed to children with diseases, such as asthma, cardiopathies, epilepsy and chronic renal failure as well as those with recurrent benign pathologies such as flu, cold, tonsillitis, otitis, allergic rhinitis and sinusitis. ${ }^{2,3}$ Antitussives and antibiotics are the most common sugar-containing medications regularly used by young children. ${ }^{4}$

Because of the bitter taste of most medications, sugar is combined with other ingredients to give a more pleasant taste and to increase the acceptance and treatment compliance of pediatric patients. ${ }^{5}$ Even though artificial substitutes, such as sodium saccharine, sodium cyclamate, aspartame and sorbitol are used, sucrose is most widely used by the pharmaceutical industry because of low cost and ease of processing. ${ }^{6}$ A study carried out to assess the sweetener content of common pediatric oral liquid medications showed that the common antibiotics had concentration ranging from 18 to $80 \%{ }^{7}$

Studies show a positive association between intake of these medications and dental caries. ${ }^{8,9}$ The medicines that have sucrose as sweetening agent also possess high viscosity that results in low salivary clearance and high cariogenic potential. ${ }^{10}$ The sugar free medications 
(SFMs) are known to be as effective as sugar-containing medications and only 10\% more expensive., ${ }^{9,11}$ However, in reality, the number of circumstances the child receive sugar free medications can not be predicted because of reasons such as prior use of the brand, perception of reliability, automatic prescribing method and the cost. ${ }^{12}$ Other factors influencing promotion of SFMs are awareness of health professionals, such as pediatrician and pharmacists. ${ }^{11,12}$

Few studies assessed the knowledge and attitude of pediatricians and pharmacists toward SFMs. ${ }^{13-15} \mathrm{~A}$ study conducted among pharmacists in Northern Ireland showed considerable lack of knowledge regarding the relationship between caries and the SFMs. ${ }^{15}$ Farias et $\mathrm{al}^{13}$ assessed the knowledge and attitude of pediatricians at a university hospital in Brazil in respect to presence of sucrose in medicines. They found that around $84 \%$ of pediatricians are unaware of this aspect and almost all of them do not recommend oral hygiene instructions to their patients and to brush their teeth after using sugary medicines. Another study conducted among pharmacists in Nigeria, established that most of them are aware of the advantages of SFMs, but their attitude toward prescribing a SFMs was not promising. ${ }^{14}$ Therefore, it can be concluded that there is considerable lack of knowledge among pediatricians and pharmacist regarding the advantages of SFMs from the dental perspective. Hence, the present survey was conducted to assess the knowledge, attitude and practice of pediatricians and pharmacists in Saudi Arabia, about sugar free medication and their potential impact on dental caries among children.

\section{MATERIALS AND METHODS}

The approval of the study and ethical clearance was obtained from College of Dentistry Research Center (CDRC), at King Saud University. A cross-sectional study was conducted among pediatricians and pharmacists in five tertiary hospitals in Riyadh (King Khalid University Hospital, King Saud Medical City, King Fahad Medical City, Prince Sultan Medical Military City and Security Forces Hospital). All participants received information on the objective of the study. The questionnaires were handed out to the pediatricians and pharmacists during the 3 months study period.

The questionnaire was closed ended questionnaire to investigate the knowledge, attitude and practice concerning SFMs. The questionnaire was modified from the work of Folayan et al. ${ }^{14}$ Questionnaire was divided into demographic data and three basic sections. The first section was about their knowledge of SFMs, source of information and awareness about sugar component in liquid oral medication. The second section was about their attitude toward SFMs. The third section was about the dispensing of SFMs, the factors influencing this decision and the instructions given to parents when dispensing SCMs.

The data were collected and analyzed using the Statistical Package for Social Sciences (IBM SPSS Statistic version 21). Descriptive statistics and Pearson's chisquare was used to observe the association between the categorical study and outcome variables. A p-value of $<0.05$ was considered as statistically significant.

\section{RESULTS}

The questionnaires were distributed to 320 pediatricians and pharmacists in five tertiary hospitals in Riyadh. Only 162 questionnaires were included in the present study after excluding the questionnaires with missing data and those who left it blank.

\section{Profile of Participants}

The demographic data regarding the pediatricians and pharmacists is given in Table 1.

Pediatricians: Eighty-five pediatricians (age $37.6 \pm 9.3$ ) responded. Most of pediatricians were male (74.1\%). The number of years of practice ranged from 2 to 20 years (mean $11.2 \pm 9.1$ ).

Pharmacists: Seventy-seven of pharmacists (age $30.8 \pm$ 6.6) responded to the questionnaire. Thirty-two of them were males (41.6\%) and 45 were females (58.4\%).

\section{Knowledge about SFMs}

The knowledge about sugar free medications among pediatricians and pharmacists are given in Table 2. Over half of pediatricians $(63.5 \%)$ have heard about sugar free medications, while (37.6\%) of them know about the sugar component of pediatric liquid oral medications. Conferences and seminars were the main source of information for most pediatricians (40\%). Only (5.9\%) have formal undergraduate training which is significantly lower than pharmacists ( $\mathrm{p}=0.04)$.

Pharmacists: Most of the respondents (72.2\%) have heard about sugar free medications, while half of them

Table 1: Demographic characteristics of participants

\begin{tabular}{lll}
\hline Characteristics & $\begin{array}{l}\text { Pediatricians } \\
(n=85) \\
\text { Mean } \pm S D\end{array}$ & $\begin{array}{l}\text { Pharmacists } \\
(n=77) \\
\text { Mean } \pm S D\end{array}$ \\
\hline Age (years) & $37.6( \pm 9.3)$ & $30.8( \pm 6.6)$ \\
Practicing years & $11.2( \pm 9.1)$ & $6.1( \pm 5.7)$ \\
Gender No. $(\%)$ & & $32(41.6 \%)$ \\
Male & $63(74.1 \%)$ & $45(58.4 \%)$ \\
Female & $22(25.9 \%)$ & \\
Nationality & & $62(80.5 \%)$ \\
Saudi & $55(64.7 \%)$ & $15(19.5 \%)$ \\
Non-Saudi & $30(35.3 \%)$ &
\end{tabular}

SD: Standard deviation 
Table 2: Knowledge of pediatricians and pharmacists about sugar free medications

\begin{tabular}{|c|c|c|c|}
\hline \multirow[t]{2}{*}{ Questions } & $\begin{array}{l}\text { Pediatricians } \\
(n=85)\end{array}$ & $\begin{array}{l}\text { Pharmacists } \\
(n=77)\end{array}$ & \multirow[t]{2}{*}{$p$-value } \\
\hline & No. (\%) & No. $(\%)$ & \\
\hline Have you heard about sugar free medications? (Yes) & $54(63.5 \%)$ & $56(72.7 \%)$ & 0.21 \\
\hline \multicolumn{4}{|l|}{ What is the source of information? ${ }^{*}$} \\
\hline Health literature & $24(28.2 \%)$ & $23(29.9 \%)$ & 0.82 \\
\hline Professional journals & $21(24.7 \%)$ & $16(20.8 \%)$ & 0.55 \\
\hline Conferences/seminars & $34(40 \%)$ & $21(27.3 \%)$ & 0.09 \\
\hline Postgraduate training & $17(20 \%)$ & $9(11.7 \%)$ & 0.15 \\
\hline Undergraduate training & $5(5.9 \%)$ & $12(15.6 \%)$ & $0.04^{* *}$ \\
\hline Other source & $11(12.9 \%)$ & $11(14.3 \%)$ & 0.8 \\
\hline Do you know the sugar component of pediatric, liquid oral medicines? (Yes) & $32(37.6 \%)$ & $38(49.4 \%)$ & 0.13 \\
\hline
\end{tabular}

*More than one answers, ${ }^{* *}$ Statistically significant

Table 3: Attitude of pediatricians and pharmacists toward sugar free medications

\begin{tabular}{|c|c|c|c|}
\hline Statements & $\begin{array}{l}\text { Pediatricians } \\
(n=85) \\
\text { No. }(\%) \\
\end{array}$ & $\begin{array}{l}\text { Pharmacists } \\
(n=77) \\
\text { No. }(\%) \\
\end{array}$ & $p$-value \\
\hline \multicolumn{4}{|c|}{ SFMs are not sweet as SCMs } \\
\hline Agree & $47(55.3 \%)$ & $44(57.1 \%)$ & \multirow{3}{*}{0.93} \\
\hline Disagree & $16(18.8 \%)$ & $15(19.5 \%)$ & \\
\hline Not sure & $22(25.9 \%)$ & $18(23.4 \%)$ & \\
\hline \multicolumn{4}{|c|}{ SFMs are less sweet and may not be acceptable } \\
\hline Agree & $34(40 \%)$ & $30(39 \%)$ & \multirow{3}{*}{0.93} \\
\hline Disagree & $30(35.3 \%)$ & $26(33.8 \%)$ & \\
\hline Not sure & $21(24.7 \%)$ & $21(27.3 \%)$ & \\
\hline \multicolumn{4}{|c|}{ SFMs are more expensive than SCMs } \\
\hline Agree & $32(37.6 \%)$ & $24(31.2 \%)$ & \multirow{3}{*}{0.48} \\
\hline Disagree & $14(16.5 \%)$ & $11(14.3 \%)$ & \\
\hline Not sure & $39(45.9 \%)$ & $42(54.5 \%)$ & \\
\hline \multicolumn{4}{|c|}{ The safety and benefits of SFMs outweigh the high cost } \\
\hline Agree & $30(35.3 \%)$ & $30(39 \%)$ & \multirow{3}{*}{0.22} \\
\hline Disagree & $20(23.5 \%)$ & $10(13 \%)$ & \\
\hline Not sure & $35(41.2 \%)$ & $37(48 \%)$ & \\
\hline \multicolumn{4}{|c|}{ Sugar content in medicine is a source of dental caries } \\
\hline Agree & $41(48.25 \%)$ & $34(44.2 \%)$ & \multirow{3}{*}{0.74} \\
\hline Disagree & $18(21.2 \%)$ & $15(19.5 \%)$ & \\
\hline Not sure & $26(30.6 \%)$ & $28(36.4 \%)$ & \\
\hline \multicolumn{4}{|c|}{ Should all liquid medications be available as SFMs? } \\
\hline Agree & $31(36.5 \%)$ & $18(23.4 \%)$ & \multirow{3}{*}{0.18} \\
\hline Disagree & $18(21.2 \%)$ & $18(23.4 \%)$ & \\
\hline Not sure & $36(42.4 \%)$ & $41(53.2 \%)$ & \\
\hline
\end{tabular}

SCMs: Sugar-containing medication; SFMs: Sugar free medications

$(49.4 \%)$ know about the sugar component of pediatric oral liquid medications. Health literature (29.9\%) and conferences $(27.3 \%)$ were the main source of information for pharmacist.

\section{Attitude toward SFMs}

The attitude of Pediatricians and pharmacists toward prescribing sugar free medications is compiled in Table 3.

Pediatricians: Half of the respondents (55.3\%) felt that the main disadvantage of SFMs is that it will be less sweet and $40 \%$ of them thought it may not be acceptable by children. Approximately one third of respondents (37.6\%) graded SFMs more expensive than SCMs, though (35.3\%) felt that the benefits from prescribing SFMs outweigh the high cost. About half (48.2\%) thought that sugar content in medicines was an important source of caries, while only (36.5\%) of respondents felt that all liquid medications should be SFMs.

Pharmacists: Similar to pediatricians, pharmacists reported same attitudes toward SFMs. 
Table 4: Practice of pediatricians (prescription) and pharmacists (dispensing) toward sugar free medication

\begin{tabular}{|c|c|c|c|}
\hline Questions & $\begin{array}{l}\text { Pediatricians } \\
(n=85) \text { No. (\%) }\end{array}$ & $\begin{array}{l}\text { Pharmacists } \\
(n=77) \text { No. (\%) }\end{array}$ & p-value \\
\hline Do you dispense or offer the choice of medication in sugar free form? (Yes) & $31(36.5 \%)$ & $24(31.2 \%)$ & 0.48 \\
\hline \multicolumn{4}{|l|}{ What are the factors that influence your decisions to dispense drugs in SFMs? ${ }^{*}$} \\
\hline Parental request & $27(31.8 \%)$ & $14(18.2 \%)$ & $0.047^{* *}$ \\
\hline Medical status of patient & $60(70.6 \%)$ & $43(55.8 \%)$ & 0.051 \\
\hline Information from health literature & $23(27.1 \%)$ & $11(14.3 \%)$ & $0.046^{\star *}$ \\
\hline Detailing by pharmaceutical representative & $27(31.8 \%)$ & $24(31.2 \%)$ & 0.93 \\
\hline Availability in pharmacy & $24(28.2 \%)$ & $50(64.9 \%)$ & $<0.0001^{* *}$ \\
\hline Recommendation by national health policy & $25(29.4 \%)$ & $21(27.3 \%)$ & 0.76 \\
\hline $\begin{array}{l}\text { Do you usually inform and guide child's parents about the risk of dental caries } \\
\text { associated with SCMs? (Yes) }\end{array}$ & $57(67.1 \%)$ & $26(33.8 \%)$ & $<0.0001^{* *}$ \\
\hline $\begin{array}{l}\text { Do you recommend child's parents oral hygiene instructions when dispensing } \\
\text { SCMs? (Yes) }\end{array}$ & $45(52.9 \%)$ & $22(28.6 \%)$ & $0.002^{* *}$ \\
\hline
\end{tabular}

${ }^{*}$ More than one answers, ${ }^{*}$ Statistically significant; SCMs: Sugar-containing medications; SFMs: Sugar free medications

\section{Practice (Prescription or Dispensing) of SFMs}

The reasons for prescribing and dispensing SFMs by pediatricians and pharmacist are depicted in Table 4.

Pediatricians: About one-third of pediatricians (36.5\%) prescribed SFMs. The main identified factor that influences the decision of those who prescribe drugs in SFMs forms was medical status of the patient. Two-thirds of pediatricians (67.1\%) informed the parents about the risk of dental caries, especially when they prescribe drugs in SCMs form. This practice was significantly higher than pharmacists $(p<0.0001)$. Almost half of the pediatricians (52.9\% gave oral hygiene instruction when prescribed SCMs. This action was significantly higher than pharmacists $(\mathrm{p}=0.002)$.

Pharmacists: One-third of pharmacists $(31.2 \%)$ dispensed SFMs. The most influencing factor affecting dispensing SFMs is availability in the pharmacy (64.9\%). Only one third of pharmacists (33.8\%) informed parents about the risk of dental caries associated with SCMs and $(28.6 \%)$ of them recommended oral hygiene instructions when dispensing SCMs.

\section{DISCUSSION}

Dental caries is one of the most common oral diseases in childhood. Its etiology is multifactorial and related to an imbalance between the tooth structure and oral environment, of which microbiota, diet and host are responsible for the disease initiation and progression. Frequent ingestion of sugars and other carbohydrates and prolonged contact of these substances with teeth are particular risk factors in the development of caries. ${ }^{16}$

Sweetened liquid medications are commonly prescribed by pediatricians to children with low compliance to tablets and capsules and are preferred due to their palatability and ease of administration. These liquid preparations contain sucrose, which can be readily fer- mented by oral acidogenic bacteria. The medicines that have sucrose as a sweetening agent possess high viscosity. As a result, these medicines have slow salivary clearance and high cariogenic potential. ${ }^{10}$

Only few studies have explored the knowledge and attitudes of medical professionals toward long-term pediatric medicines with sucrose and the risk of having dental caries in children. This study not only shows the differences in knowledge, attitudes and practices of pediatricians and pharmacists with respect to sugar free medications, but also indicates the areas of advocacy and education about SFMs. Sweeteners are added to pediatric formulations to mask the unpleasant taste of the active ingredients. Because of the popularity of these preparations, the manufacturing industry has been reluctant to take out the sugar from these preparations. The preference of cheaper generic preparations had been identified as a particular problem since they contain more sugar than their proprietary equivalents. ${ }^{17}$ In fact, it is possible to produce sugar free medicines which were just as effective, safe and acceptable as their sugar-containing equivalents. The pharmaceutical companies manufacturing the SFMs is around 10\% more expensive than the one containing sucrose. ${ }^{11}$

Even though the pediatricians and pharmacists are aware of the deleterious effects of these medications, they did not give enough importance to this issue which is in agreement with previous study. ${ }^{14}$ It was observed that pharmacists' responses regarding knowledge about these medications were gained during undergraduate training. Some pharmacists received the information informally after graduation. Some of them were unsure of the medications they should be giving and would benefit from further education on this issue. The need for an educational input at undergraduate level is obvious, as is the need for continuing training after graduation in order to remain up-to-date with the changing situation..$^{15}$ This 
finding was similar to McVeigh and Kinirons ${ }^{15}$ findings. Although, amongst medical professionals the awareness seems to be high, more than half of pharmacists and pediatricians believed that SFMs are not sweet as SCMs, but in fact SFMs are actually sweet but they don not contain sucrose in their composition which is the main source of dental caries. This response could be attributed to the low awareness about sugar content in medicines which can be sweetened with other anticariogenic and antiacidogenic sweetening agents like xylitol, mannitol and sorbitol. ${ }^{18}$ Other misconception about SFMs could be attributed to the term (sugar-free) as they thought it's synonym to (sweet-free), therefore the use of (sucrosefree) or (noncariogenic medication) could improve the attitude toward SFMs.

Similar to study by Folayan et $\mathrm{al}^{14}{ }^{14} 30 \%$ of pharmacists believed that SFMs are more expensive than SCMs while, the same number thought that safety and benefits outweigh this higher cost difference. Definitely it is true when it comes to reality that the higher cost difference that are spent in those safe medicines protect patients from further medical and dental complications which also need more higher cost of what is afforded. Less than third (23.4\%) of pharmacists in our study are of the opinion that all medication should be in sugar-free-form which is in agreement with the study by Folayan et al. In contrast, $87 \%$ of the pharmacists in Belfast felt that all medication should be available in sugar-free form. ${ }^{15}$ This positive attitude noticed in Belfast is attributed to the pressure applied by British Association of Community Dentistry and increased awareness of consumers regarding the benefit of SFMs. ${ }^{11}$ This finding emphasis the role of dental societies to implement the rules that could improve the oral health of the society.

In most of the studies, the availability of the medication played a major role in dispensing the SFMs. ${ }^{14,15}$ One way to enhance dispensing of SFMs is to prescribe by proprietary name or specify in the prescription sugarfree product. ${ }^{17}$ Majority of pediatricians showed greater response than pharmacists in informing and guiding their child's parents about the risk of dental caries associated with SCMs. They also showed better attention toward providing oral hygiene instructions to the child's parents. This may be attributed to the fact that pediatricians are more frequently in a direct contact through a long period of the time with their patients than pharmacists. The pediatricians and pharmacists have a golden opportunity to inform and guide the parents of the children about the risk of dental caries, and explain how they can prevent its incidence through recommending appropriate oral hygiene instructions and taking medication preferably at meal times, when using sugar medicines regularly.
The dental profession should continue to take the initiative in the promotion of SFMs and in the provision of necessary education at the undergraduate and postgraduate level as well as during continuing professional education. However, education of other health professionals is also essential if SFMs are to be perceived as a significant component of dental health promotion. The health professionals have good opportunity to inform and guide the parents of children about the risk of dental caries, and explain the preventive methods by oral hygiene maintenance.

\section{CONCLUSION}

Reducing the cariogenic potential of children's medications should be of concern to all health professionals. On the contary, manufacturing children's medicines containing no fermentable carbohydrates should be the best public health policy. Noncariogenic or SFMs should be prescribed whenever possible. Considering the cariogenic potential of sweetened medications prescribed to children, it is important that health professionals, especially pediatricians and pharmacists, are engaged in educating parents to ensure adequate oral clearance after each dose of medication as a primary step for minimizing the risk of dental caries.

\section{ACKNOWLEDGMENT}

The study was supported by CDRC (\# IR 0085) in King Saud University at Riyadh, Saudi Arabia. We would like to thank all the participants for their time and effort in completing the questionnaires.

\section{REFERENCES}

1. Shaw L, Glenwright HD. The role of medications in dental caries formation: need for sugar free medication for children. Pediatrician 1989;16(3-4):153-155.

2. Steinbacher DM, Glick M. The dental patient with asthma. An update and oral health considerations. J Am Dent Assoc 2001;132(9):1229-1239.

3. Peres KG, Oliveira CT, Peres MA, Raymundo Mdos S, Fett R. Sugar content in liquid oral medicines for children. Rev Saude Publica 2005;39(3):486-489.

4. Cavalcanti AL, Fernandes LV, Barbosa AS, Vieira FF. pH, titratable acidity acidity and total soluble solid content of pediatric antitussive medicines. Acta Stomatol Croat 2008; 42(2):164-170.

5. Hobson P. Sugar based medicines and dental disease. Community Dent Health 1985;2(1):57-62.

6. Kumar A, Rawlings RD, Beaman DC. The mystery ingredients: sweeteners, flavorings, dyes and preservatives in analgesic/antipyretic, antihistamine/decongestant, cough and cold, antidiarrheal, and liquid theophylline preparations. Pediatrics 1993;91(5):927-933. 
7. Hill EM, Flaitz CM, Frost GR. Sweetener content of common pediatric oral liquid medications. Am J Hosp Pharm 1988; 45(1):135-142.

8. Chu F, Siu A, Yip H, Terezhalmy G, Riley C, Moore W. Rampant caries secondary to cough syrup addiction. Quintessence International 2001;32:78-79.

9. Bigeard L. The role of medication and sugars in pediatric dental patients. Dent Clin North Am 2000;44(3):443-456.

10. Durward $C$, Thou T. Dental caries and sugar-containing liquid medicines for children in New Zealand. N Z Dent J 1997;93(414):124-129.

11. Mackie IC, Hobson P. Factors affecting the availability of sugar free medicines for children-a survey in the UK. Int J Paediatr Dent 1993;3(3):163-167.

12. Hunter ML, Lewis R, Hunter B. Consumer demand in the purchase and prescription of sugar free medicines. Int $\mathrm{J}$ Paediatr Dent 2000;10(2):140-144.

13. Farias IAP, F.C. S, Freitas CHS. Long-term pediatric sugared medicines: knowledge and attitude of medical practi- tioners at a university hospital. Rev Gaúcha Odontol 2011;59: 599-602.

14. Folayan MO, Bankole OO, Osaguona A, Fatusi O, Oyedele T, Ashiwaju MO. A survey of knowledge, opinion and practice of dentists, pharmacists and parents in Nigeria towards the use of sugar free medication. European J Paediatric Dentist 2012;13(2):136-142.

15. McVeigh N, Kinirons MJ. Pharmacists' knowledge, attitudes and practices concerning sugar free medicines. Int J Paediatr Dent 1999;9(1):31-35.

16. Low W, Tan S, Schwartz S. The effect of severe caries on the quality of life in young children. Pediatr Dent 1999;21(6): 325-326.

17. Maguire A, Rugg-Gunn AJ. Medicines in liquid and syrup form used long-term in paediatrics: a survey in the Northern Region of England. Int J Paediatr Dent 1994;4(2):93-99.

18. Frostell G, Keyes PH, Larson RH. Effect of various sugars and sugar substitutes on dental caries in hamsters and rats. J Nutr 1967;93(1):65-76. 